OPEN ACCESS

Edited by:

Jason Bell,

The University of Western Australia,

Australia

Reviewed by:

Ulrich Schweiger,

Universität zu Lübeck, Germany Naomi Kakoschke,

Monash University, Australia

${ }^{*}$ Correspondence:

Jang-Han Lee

clipsy@cau.ac.k

Specialty section:

This article was submitted to Eating Behavior,

a section of the journal

Frontiers in Psychology

Received: 11 March 2019

Accepted: 29 July 2019

Published: 13 August 2019

Citation:

Kim J, Kim K and Lee J-H (2019) The Effect of Neuroticism Level on Restrained Eaters' Thinness Fantasy

and Attentional Bias for Food.

Front. Psychol. 10:1850.

doi: 10.3389/fpsyg.2019.01850

\section{The Effect of Neuroticism Level on Restrained Eaters' Thinness Fantasy and Attentional Bias for Food}

\author{
Jihyang Kim ${ }^{1}$, Kiho Kim ${ }^{1}$ and Jang-Han Lee ${ }^{2 *}$ \\ ${ }^{1}$ Department of Psychology, Chung-Ang University, Seoul, South Korea, ${ }^{2}$ Department of Psychology, Chung-Ang University, \\ Seoul, South Korea
}

The aim of this study was to examine the role of restrained eaters' neuroticism level in thinness fantasy and attentional bias for food following exposure to thin-ideal images. Eighty-five female participants were classified into four groups on the basis of their dietary restraint (restrained/unrestrained eaters) and neuroticism level (high/low). They completed self-reports (mood, body dissatisfaction level) on a visual analog scale before and after exposure to thin-ideal images, and then their attentional bias for food was measured using eye-movements. Results indicated that after exposure to thin-ideal images, positive affect was more decreased in restrained eaters with high neuroticism compared to other groups and negative affect was increased in all groups except unrestrained eaters with low neuroticism. Also, restrained eaters with high neuroticism showed a heightened vigilance for food. These findings underscore the role of neuroticism in restrained eaters as a moderating factor of thinness fantasy.

Keywords: restrained eaters, neuroticism, thinness fantasy, attentional bias, body image

\section{INTRODUCTION}

Dietary restraint refers to intentional individual efforts to limit food intake for weight loss or weight control (Herman and Polivy, 1975); the behavior increases risk for onset and maintenance disordered eating such as binge eating and bulimic symptoms (Stice, 2001). Thin-ideal images from mass media are one main risk factor for restrained eating (Anschutz et al., 2011) because restrained eaters are preoccupied with their weight and perceived shape. Images portrayed in the mass media depicting extremely thin and attractive bodies influences restrained eaters, and for some, they set a goal of emulating the thin-ideals portrayed.

When restrained eaters are exposed to thin-ideal images from mass media, these images can sometimes lead to "thinness fantasy" (Mills et al., 2002). Thinness fantasy is cognitive processing that restrained eaters perceive the thin-ideal goal as personally attainable; they believe or fantasize that they can also be thinner in order to achieve the ideal body. This makes them feel thinner, and self-enhancement, such as increased positive affect and body-esteem, and temporarily disinhibit their eating (Mills et al., 2002). For example, restrained eaters who viewed commercial advertisements depicting thin models consumed more food than others who viewed plus size model or product-only advertisements (Warren et al., 2005).

Some replication studies of the impact of thinness fantasy in restrained eaters failed to find evidence of the self-enhancement effect; rather, they showed an increase of negative affect and body dissatisfaction (BD) following exposure to thin-ideal images (Boyce et al., 2013). 
Individual differences such as neuroticism and conscientiousness, as a moderating factor between exposure to thin-ideal images and restrained eaters' body images may explain the differential of responses to thin-ideal images of restrained eaters and should be investigated (e.g., Roberts and Good, 2010).

A recent study (Roberts and Good, 2010) posited that neuroticism may be the factor that can explain the inconsistency in the media exposure literature, this is because: only neuroticism listed among the Five-Factor traits was associated with the harmful effect of thin-ideal images. Neuroticism refers to individual differences in emotional lability and adjustment (Costa and McCrae, 1992). When individuals exhibit a high level of neuroticism, they are more likely to be emotionally unstable, experiencing myriad negative affects such as anxiety, hostility, depression, self-consciousness, impulsiveness, and vulnerability (Widiger et al., 2002). Also, they tend to be more reactive to potentially threatening stimuli and prone to avoid them (Rusting, 1998). In the previous study (Roberts and Good, 2010), women with a high level of neuroticism showed a greater decrease of body-esteem and body satisfaction than those with low neuroticism after viewing ideal body images. This is because, in general, exposure to images of exceptionally thin attractive women can be perceived as emotionally threatening to women (Bergstrom et al., 2009) and cause upward social comparison leading to negative affect and low body-esteem. That is, these negative effects appear according to ones' neuroticism level because individuals with high neuroticism are emotionally unstable and experience upward social comparison more frequently than those with low neuroticism (Van der Zee et al., 1999). The results of previous studies, however, do not suggest that women with low levels of neuroticism may experience increased positive affect following exposure to thinideal images. Although the relationship between low neuroticism and positive affect in women has not been clarified thus far, given that neuroticism has positively associated to negative affect and $\mathrm{BD}$, it is expected that compared to restrained eaters with high neuroticism, restrained eaters with low neuroticism may experience more self-enhancement effect after viewing thin-ideal images.

Another important effect of neuroticism on restrained eaters is that it plays a role in the pathological development from restrained eating to bulimia (Heaven et al., 2001). The negative affect that restrained eaters experience after viewing thin-ideal images is related to their dieting goal and thus causes extreme restriction of food intake (Boyce et al., 2013), but they usually fail to maintain their control resulting in overeating. Although most previous studies on media images and food intake in restrained eaters have shown that thin-ideal media images are related to restrained eaters' food intake, the results are still unclear. Some research has showed increase of food intake after exposure to media images (Mills et al., 2002; Anschutz et al., 2011), while other research showed a decrease of food intake (Strahan et al., 2007), or non-significant effect (Boyce et al., 2013). One reason for the inconsistent results may be that in previous research, taste tests were used not considering whether they had the tendency to restrict food intake. Also, using direct measures (such as taste tests) are likely to be confounded by reporting bias such as demand characteristics (Mills et al., 2002) and social desirability (Brignell et al., 2009). For this reason, in this study, attentional bias for food was measured using an eye-tracking system. Attentional bias is useful to determine the potential mechanism underpinning the relationship between exposure to thin-ideal images and food consumption.

Attentional bias occurs when emotional salient stimuli are preferentially processed compared to neutral stimuli; it also reflects the cognitive and motivational processing of emotional information (Cisler and Koster, 2010). Early attentional bias (vigilance) reflects an automatic process and speeded detection to a salient stimulus (e.g., threat) or the incentive value of the stimulus while later attentional bias (maintenance or avoidance) reflects a strategic process (Berridge, 2009; Cisler and Koster, 2010). In order to demonstrate attention bias toward food cues, several studies have used the Stroop test or a visual probe task (Dobson and Dozois, 2004; Rofey et al., 2004). However, the results of attention bias were limited in explaining both the initial and later stages of attention, as the Stroop test and the visual probe task were not sufficient in identifying these stages of the attention process. Because these measures based on reaction time which provide only an indirect assessment of attention allocation and do not investigate for shifting of attention between stimuli (Miller and Fillmore, 2010). Using an eye-tracking system, vigilance bias can be measured with the gaze direction and initial fixation duration, and avoidance bias can be measured with gaze duration. A previous study (Hollitt et al., 2010) that measured attentional bias for food in restrained eaters have demonstrated that restrained eaters showed a heightened vigilance for food cues but no differences in disengagement compared to unrestrained eaters. As for restrained eaters, food cues potentially threaten their dietary goal, if restrained eaters' neuroticism is higher, they would show stronger vigilance-avoidance pattern of attention for food.

Overall, the aim of the present study was to investigate whether neuroticism influences mood and $\mathrm{BD}$ of restrained eaters following exposure to thin-ideal images and to examine the attentional bias for food in them using an eye-tracker.

\section{MATERIALS AND METHODS}

\section{Participants and Screening}

Four hundred seventy-five female undergraduate students were recruited, and eighty-five students $\left(M_{\text {age }}=22.81 \pm 1.59\right.$, $\left.M_{\mathrm{BMI}}=20.13 \pm 2.04\right)$ ultimately participated in this study. Based on the previous research concerning categorizing participants into four groups based on restraint/neuroticism (Kim and Lee, 2016), participants were selected only if they belonged to the upper or lower $25 \%$ of the dietary restraint (a score under 39 or over 51) and neuroticism level (a score under 135 or over 149) using Restraint Scale (RS; Herman and Polivy, 1980) and neuroticism items in Revised NEO Personality Inventory (NEOPI-R; Costa and McCrae, 1992), respectively. They were divided into four groups: restrained eaters with high neuroticism (R-H), restrained eaters with low neuroticism (R-L), unrestrained eaters 
with high neuroticism (U-H) and unrestrained eaters with low neuroticism (U-L).

\section{Materials and Apparatus Restraint Scale (RS)}

Restraint Scale (Herman and Polivy, 1980) was used for screening participants. RS consists of 15 items measuring dietary restraint behaviors. Participants responded on a 7 -point Likert scale ranging from 0 (not at all) to 6 (very much so). The total score ranged from 0 to 90 ; higher total scores are indicative of dietary restraint. Cronbach's alpha in the present study was 0.92 .

\section{Revised NEO Personality Inventory (NEO-PI-R)}

The neuroticism subscale of NEO-PI-R (Costa and McCrae, 1992) was also used for screening participants. This scale includes 48 items and measures an individual's neuroticism level. Each item is rated from 1 (not at all) to 5 (very much so). The total score ranges from 48 to 240 with a higher the score indicating a greater level of neuroticism. Cronbach's alpha in the present study was 0.93 .

\section{Visual Analog Scale (VAS)}

A VAS (Heinberg and Thompson, 1995) was used to assess changes in mood and BD level. The VAS consisted of $100 \mathrm{~mm}$ horizontal line (0: not at all; 100: very much).

\section{Thin-Ideal Images}

Thirty commercial images depicting a typical ultra-thin female model were collected from fashion magazines. For validation of the thin-ideal images construct, fourteen female undergraduate students, who did not participate in this study, were asked to rate the attractiveness, valence, and arousal of the images on a 7-point Likert scale ranging from 1 (not at all) to 7 (very much so). Based on the results of the students' ratings, fifteen images were chosen that were rated relatively attractive. Each image was presented for $20 \mathrm{~s}$ on a monitor screen. All pictures were $150 \mathrm{~mm}$ high $\times 100 \mathrm{~mm}$ width.

\section{Free-Viewing Task}

A free-viewing task was used to record the participants' eye movements to food pictures. Each trial started with a central fixation cross for $1000 \mathrm{~ms}$ and then a picture pair was presented for $2000 \mathrm{~ms}$, followed by a blank screen for $500 \mathrm{~ms}$. Participants were asked to look at the pictures on the screen as if they were watching television and to focus on the fixation cross between trials. A total of 64 trials, including four practice trials and 60 main trials (20 critical and 40 filler trials), were conducted. During the critical trials, each of the 10 highly palatable food pictures (e.g., chips) was paired with a matched control picture (e.g., crayons) as closely as possible for physical properties such as color and visual complexity, and then pretested for palatability, valence, and arousal. In addition, 20 pairs of non-food pictures were selected for filler trials and two pairs for practice trials. The stimuli were displayed side-by-side in pairs on a 21 -inch wide monitor screen $(1680 \times 1050$ pixels $)$; all pictures were approximately $75 \mathrm{~mm}$ high $\mathrm{x} 138 \mathrm{~mm}$ width. The locations of food and control stimuli were counterbalanced across trials.
The participants' eye-movements were recorded by the iView XTM Red-IV Eye Tracking System (SensoMotoric Instruments, Berlin, Germany).

\section{Procedure}

At the beginning of the experiment, participants were provided with an informed consent form and asked to report their positive and negative affect and BD level on a VAS. Subsequently, they were exposed to fifteen thin-ideal images for a total of $5 \mathrm{~min}$, rating the attractiveness of each model. They then reported their positive and negative affect and BD level on the VAS again and performed the free-viewing task. Finally, they were debriefed and provided with a $\$ 5$ gift card.

\section{Data Analysis}

Attentional bias scores from the eye-movement data were used in the analyses based on previous study (Werthmann et al., 2011). One participant's data was removed from the eye-movement analysis due to data input error in the eye-tracking system. The direction bias score was calculated for each participant by computing the percentage of initial fixations on the food pictures of all trials on which a first fixation was made to either food or control picture. The bias score greater than $50 \%$ reflects a higher proportion of first fixations directed to food cues, that is, vigilance toward food pictures. The initial fixation duration bias score was calculated for each participant by subtracting the mean duration of initial fixations on the control pictures from the mean duration of initial fixations on the food pictures. Positive scores reflect vigilance toward food pictures. The gaze duration bias score was calculated for each participant by subtracting the mean gaze duration on the control pictures from the mean gaze duration on the food pictures. Positive scores reflect attentional maintenance (less avoidance) toward food pictures.

A 2 (restraint status: restrained, unrestrained) $\times 2$ (neuroticism: high, low) Analysis of Variance (ANOVA) was used to analyze participants' characteristics, mood and BD change and the eye-movement data, including gaze direction, initial fixation duration and gaze duration. SPSS 18.0 for Windows was used for the analyses.

\section{RESULTS}

\section{Group Characteristics}

The mean age and BMI were not significantly different among groups (all ns); however, RS and NEO-PI-R scores were significantly different. Regarding the restraint status, $\mathrm{R}-\mathrm{H}$ group and R-L group had higher scores in RS compared to U-H group and U-L group $\left(F(1,81)=420.51, p<0.001, \eta_{\mathrm{p}}{ }^{2}=0.84\right)$. Regarding the neuroticism, R-H group and $\mathrm{U}-\mathrm{H}$ group had higher scores in NEO-PI-R compared to R-L group and U-L group $\left(F(1,81)=373.04, p<0.001, \eta_{p}{ }^{2}=0.82\right)$. These group differences for restraint and neuroticism were expected given that participants were allocated to such groups based on their scores on these measures. Data on these variables are displayed in Table 1. 
TABLE 1 | Mean $(S D)$ values for age, BMI, RS, and NEO-PI-R.

\begin{tabular}{lccccc}
\hline & \multicolumn{2}{c}{ Restrained eaters } & & \multicolumn{2}{c}{ Unrestrained eaters } \\
\cline { 2 - 3 } \cline { 6 - 6 } & High N & Low N & & High N & Low N \\
& $(\boldsymbol{n}=\mathbf{2 1})$ & $(\boldsymbol{n}=\mathbf{2 2})$ & & $(\boldsymbol{n}=\mathbf{2 1})$ & $(\boldsymbol{n}=\mathbf{2 1})$ \\
\hline Age & $22.71(1.65)$ & $23.14(1.50)$ & & $22.29(1.62)$ & $23.10(1.55)$ \\
BMl & $20.70(1.98)$ & $20.20(1.52)$ & & $19.86(2.63)$ & $19.78(1.93)$ \\
RS & $62.76(7.27)$ & $63.55(8.20)$ & & $24.29(9.63)$ & $26.00(8.90)$ \\
NEO-PI-R & $167.33(9.82)$ & $122.45(9.61)$ & & $167.52(13.27)$ & $122.38(9.90)$
\end{tabular}

High N, high neuroticism; Low N, low neuroticism; RS, Restraint Scale; NEO-PI-R, revised NEO personality inventory.

\section{Mood and Body Dissatisfaction Changes}

Mood and BD level change was calculated for each participant by subtracting the pre-VAS score from the post-VAS score. A positive score reflects the increase of positive affect, negative affect, and BD level following exposure to thin-ideal images. Four participants' data and six participants' data were excluded in positive affect and $\mathrm{BD}$, respectively, because their scores were more than 2 standard deviations greater than the mean of their respective group.

Regarding positive affect, there was a significant interaction between restraint status and neuroticism $(F(1,75)=4.12$, $\left.p<0.05, \eta_{\mathrm{p}}^{2}=0.05\right)$, and a significant main effect of restraint status $\left(F(1,75)=6.68, p<0.05, \eta_{\mathrm{p}}{ }^{2}=0.08\right)$. A simple main effects analysis indicated that the $\mathrm{R}-\mathrm{H}$ group reported a greater decrease of positive affect when compared to the R-L group $(F(1,75)=5.78$, $p<0.05)$ and $\mathrm{U}-\mathrm{H}$ group $(F(1,75)=10.78, p<0.01)$.

Regarding negative affect, there was a significant interaction between restraint status and neuroticism $(F(1,81)=4.10$, $\left.p<0.05, \eta_{\mathrm{p}}^{2}=0.05\right)$. A simple main effects analysis revealed significant differences between the U-L group and U-H group $(F(1,81)=5.39, p<0.05)$ and $\mathrm{U}-\mathrm{L}$ group and R-L group $(F(1,81)=5.85, p<0.05)$. That is, there were no significant differences in negative affect following exposure to thin-ideal images between individuals with high levels of neuroticism and those with low levels of neuroticism in restrained eaters. Individuals with high neuroticism reported significantly more negative affect than those with low neuroticism in unrestrained eaters.

Lastly, regarding $\mathrm{BD}$, there was a significant main effect of neuroticism $\left(F(1,77)=4.51, p<0.05, \eta_{\mathrm{p}}{ }^{2}=0.06\right)$ : individuals with high levels of neuroticism reported a greater increase of $\mathrm{BD}$ level compared to those with low neuroticism.

\section{Eye-Movement Data}

The gaze direction and an initial fixation duration bias scores were calculated for vigilance bias. There was a significant interaction between restraint status and neuroticism for the gaze direction bias score $\left(F(1,80)=6.37, p<0.05, \eta_{\mathrm{p}}{ }^{2}=0.07\right)$. A simple main effects analysis indicated that $\mathrm{R}-\mathrm{H}$ group and $\mathrm{U}-\mathrm{L}$ group showed more attentional orienting toward food pictures compared to R-L group $(F(1,80)=6.60, p<0.05 ; F(1,80)=6.34$, $p<0.05)$. The results of the gaze direction bias scores are displayed in Figure 1A. There were no significant effects for the initial fixation duration bias score.

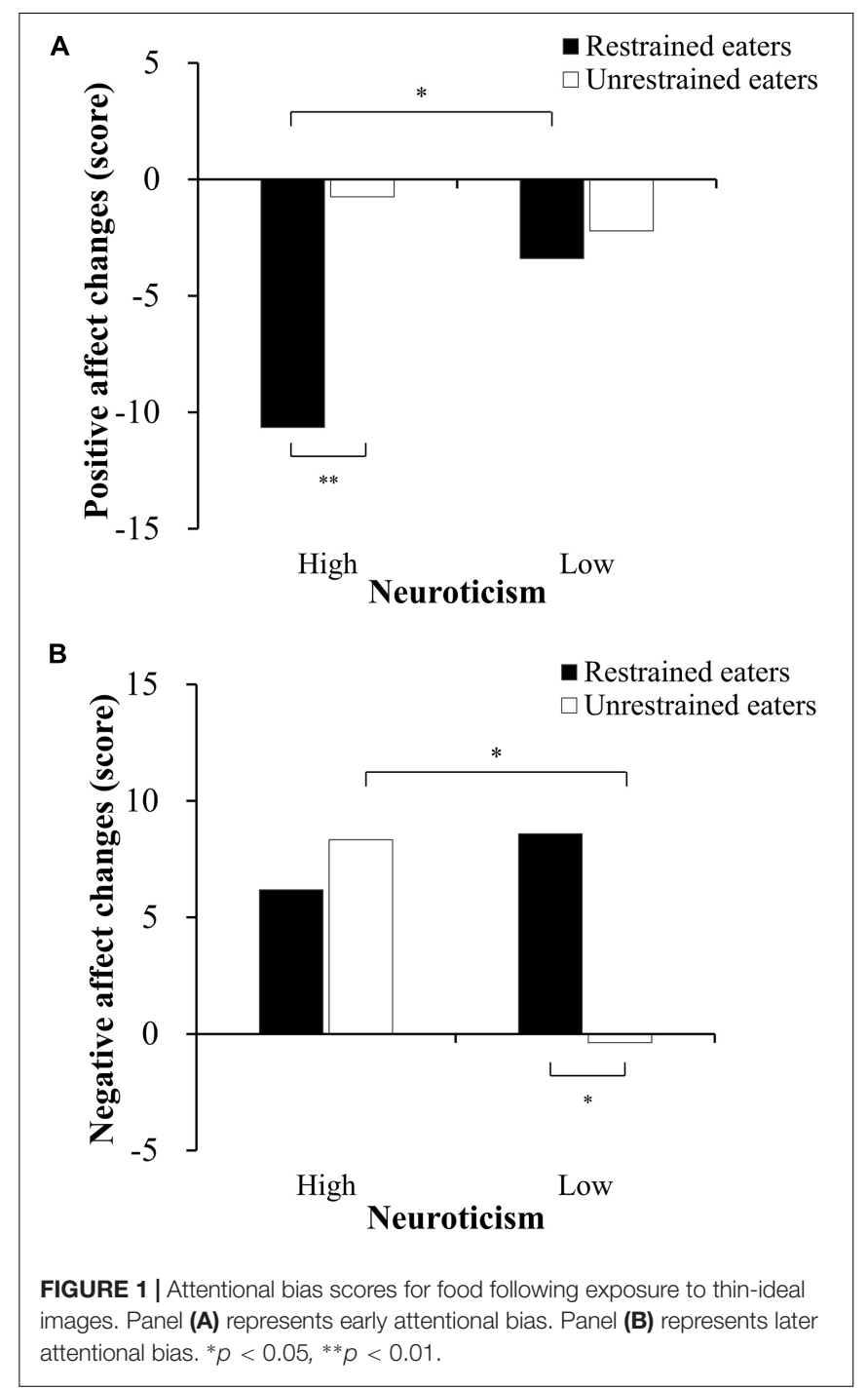

The gaze duration bias score was calculated for avoidance bias. There was a significant main effect of restraint status for the gaze duration bias score $(F(1,80)=10.51, p<0.01$, $\left.\eta_{\mathrm{p}}^{2}=0.12\right)$. Compared to restrained eaters, unrestrained eaters gazed significantly longer on the food pictures than the control pictures. The results of the gaze duration bias scores are displayed in Figure 1B.

\section{DISCUSSION}

The present study investigated the effect of neuroticism on restrained eaters' thinness fantasy and attentional bias for food following exposure to thin-ideal images. The changes between pre- and post-VAS scores of mood and BD level revealed that all groups experienced a decrease of positive affect and increase of negative affect and $\mathrm{BD}$, except in the case of unrestrained eaters with low neuroticism in negative affect. In particular, restrained eaters with high neuroticism, when compared to the other groups, showed greatly decreased positive affect following 
exposure to thin-ideal images, which was consistent with the original study hypothesis. In addition, restrained eaters reported a greater increase of negative affect than unrestrained eaters regardless of their neuroticism level, and individuals with high neuroticism showed a greater increase of BD than individuals with low neuroticism regardless of their restraint status. These results suggest that as one's dietary restraint is more severe and one's neuroticism level is higher, the person becomes more likely to experience deleterious effects from thin-ideal images. Thus, the results of the study seem to be consistent with those of recent studies that, suggest: restrained eaters do not exhibit the selfenhancement effect from thin-ideal images (e.g., Boyce et al., 2013) compared with previous research on restrained eaters' thinness fantasy (e.g., Mills et al., 2002). Especially, this also supports the concept that neuroticism moderates the harmful effect of thin-ideal images in women (Roberts and Good, 2010).

The self-enhancement effect of restrained eaters was not found in the present study. Rather, all restrained eaters showed a decrease of positive affect and increase of negative affect and BD. One possible reason for this is that an individual's neuroticism, which is susceptible to negative emotions, may not be fully responsible for the increase of positive affect after viewing thinideal images in restrained eaters. That is, although neuroticism screening items used in this study measured participants' level of emotional instability, the individual's neuroticism level defined as a function of the low score cannot unequivocally represent the person's emotional stability. Therefore, it is possible that when restrained eaters have emotionally stable trait, such as conscientiousness which is associated with confidence and self-efficacy, (Roberts and Good, 2010), thinideal images may increase their positive affect. To investigate this potential relationship, further studies should also consider, in addition to measures of emotional instability, countervailing stable personality traits that can promote positive emotions in restrained eaters.

Based on the analysis of eye-movement data, the $\mathrm{R}-\mathrm{H}$ group and $\mathrm{U}-\mathrm{L}$ group directed their initial orientations more often toward food in comparison with the R-L group. In addition, overall attentional maintenance toward food was substantially more intense in unrestrained eaters than in restrained eaters. This attentional pattern observed in the $\mathrm{R}-\mathrm{H}$ group can be interpreted as heightened vigilance-avoidance for food compared to the gaze pattern of other groups. This suggests that when exposed to highly palatable food, the R-H group may have an initial orientation bias toward food cues but avert their eyes from them to avoid the dietary goal threat (Wegner, 1994). These findings support and extend the results of Hollitt et al. (2010) which examined restrained eaters' attentional bias for food using a visual search task. In the study, restrained eaters showed heightened vigilance for food cues, but the visual search task used in the study provided indirect evidence of attentional bias, which is only a discontinuous response prior to behavioral responses (Hermans et al., 1999). The present study, however, demonstrated restrained eaters' early attentional bias and avoidance pattern for food following exposure to thin-ideal images by measuring continuous attentional processing using the eye-tracking system. In particular, the result of early attentional bias for food in restrained eaters suggests that the vigilance bias for food increased along with their neuroticism level.

Overall, the results of the present study indicate that thinideal images from media sources can lead to negative mood in restrained eaters leading to vigilance-avoidance pattern for food and BD in individuals with high levels of neuroticism. Thin-ideal images depicting extremely thin and attractive bodies inspire many women, especially restrained eaters, and compel them to set a goal of emulating the thin-ideals that they see on the screen. Generally, this cognitive process induces upward social comparison among the restrained eaters. When women including restrained eaters are exposed to media images of thinideal, they compare themselves with the thin-ideal images and focus on areas where they are perceived to be worse. If their goal is higher, it is harder to fulfill, and thus they will have greater self-discrepancy, resulting in increase of negative mood and BD (Krahé and Krause, 2010). According to control theory (Carver and Scheier, 1982) and reinhibition theory (Strauss et al., 1994), the negative mood and BD induced from perceived discrepancy between their present condition and the thin-ideal body triggers goal-related behavior such as restrained eating. In this cognitive process, neuroticism serves as a contributing factor to heightened negative mood and BD because individuals with high levels of neuroticism have more tendencies to make upward comparison than individuals with low levels of neuroticism (Van der Zee et al., 1999; Roberts and Good, 2010). For this reason, it seems that not only R-H group, but also the R-L group and $\mathrm{U}-\mathrm{H}$ group experienced an increase of negative affect and BD. However, as unrestrained eaters with high neuroticism are not related to dietary restraint, they might not show a vigilanceavoidance pattern of visual attention for food, while restrained eaters with high levels of neuroticism showed the most severe vigilance-avoidance pattern.

Our findings suggest several implications. First, to the best of our knowledge, this is the first study to examine the moderating factor of restrained eaters' thinness fantasy following exposure to thin-ideal images considering their personality traits. Previous studies have shown mixed results regarding restrained eaters' thinness fantasy when compared with unrestrained eaters. In the present study, however, participants were divided into four groups according to both their restraint status and level of neuroticism. Although the self-enhancement effect was not observed in the group, restrained eaters with high levels of neuroticism felt less positive affect and more BD than restrained eaters with low levels of neuroticism. These results highlight the importance of neuroticism as a moderator in the relationship between thin-ideal images and restrained eaters. Second, the results of this study may provide indirect evidence of highly neurotic restrained eaters' goal efforts by identifying a vigilanceavoidance pattern of visual attention for food. Although the gaze duration bias was not significantly different between the $\mathrm{R}-\mathrm{H}$ group and $\mathrm{R}-\mathrm{L}$ group, both groups had tendencies to avoid food, and the R-H group showed more intense early vigilance toward food, in line with the results of mood and $\mathrm{BD}$. These results also align with the previous study (Boyce et al., 2013), which suggested that negative affect might encourage restrained eaters' goal-related behaviors. In future studies, it may 
be necessary to identify how much either negative affect or BD contributes to highly neurotic restrained eaters' goal efforts. Finally, the results from the present study could be helpful in clinical settings for designing intervention of patients with excessive restrained eating. Even if restrained eaters experience self-enhancement following exposure to thin-ideal images, in the long term, it can be a maintenance mechanism of restrained eating by seeking out these images to have positive feelings. Thus, it is fundamentally important to change restrained eaters' ideal body images from unattainable and unrealistic body images to healthy and attractive body images. Additionally, some coping strategies such as emotional regulation or the modification of attentional bias for food should be a consideration for restrained eaters with high neuroticism who are especially susceptible to thin-ideal images. Furthermore, other proper therapies according to weight or shape of restrained eaters or need for health should be considered for future research.

Despite the study's numerous contributions, there are some notable limitations. First, there were no direct measures of thinness fantasy. Although mood and BD level were utilized as proxies to represent the extent of thinness fantasy based on the previous studies (e.g., Mills et al., 2002; Boyce et al., 2013), future studies should focus on identifying a more direct representation of thinness fantasy such as the Thin Fantasy Scale (Talesfore, 2008). Second, the present study used VAS to measure participants' mood and BD changes. Although the data showed some significant differences among groups, the selfreport data can be distorted due to social desirability or demand characteristics (Mills et al., 2002; Brignell et al., 2009). Given these acknowledged limitations, future studies may benefit from assessing participants' subjective feelings using indirect methods. Third, this study used a quasi-experimental design rather than an experimental design. A quasi-experimental design is similar to traditional experimental design or randomized controlled trial, but it specifically lacks the factor of random assignment to treatment or control. Thus, in a follow-up study, it would be useful to use an experimental design to compare the effects of different types of images (e.g., thin-ideal versus other body type or neutral images). Finally, this study did not directly investigate the relation between negative affect and attentional bias for food. Although the vigilance-avoidance pattern for food of restrained eaters can be interpreted as their effort to avoid goal threat (Hollitt et al., 2010; Boyce et al., 2013), the results could not conclusively demonstrate the putative relationship. Thus, it would be interesting to investigate how negative affect or $\mathrm{BD}$ is related to restrained eaters' dietary goal and how it influences implicit cognitive processing of food or actual eating behavior.

\section{REFERENCES}

Anschutz, D. J., Van Strien, T., and Engels, R. C. (2011). Exposure to slim images in mass media: television commercials as reminders of restriction in restrained eaters. Health Psychol. 27, 401-448. doi: 10.1037/0278-6133.27. 4.401

Bergstrom, R. L., Neighbors, C., and Malheim, J. E. (2009). Media comparisons and threats to body image: seeking evidence of selfaffirmation. J. Soc. Clin. Psychol. 28, 264-280. doi: 10.1521/jscp.2009.28. 2.264

\section{CONCLUSION}

In conclusion, the current study demonstrated that restrained eaters with high neuroticism are the most vulnerable to thin-ideal images. They felt negative feelings and showed the most intense vigilance-avoidance pattern for food after exposure to thin-ideal images. These results highlight the importance of clarifying the individual differences moderating the harmful effect of thin-ideal images. Additionally, this study extends our understanding of the role of neuroticism and thinness fantasy in restrained eaters.

\section{AUTHOR'S NOTE}

This study is an extended version of work that was presented in the 17th European Conference on Personality.

\section{DATA AVAILABILITY}

All datasets generated for this study are included in the manuscript and/or the supplementary files.

\section{ETHICS STATEMENT}

This study was carried out in accordance with the recommendations of "the Institutional Review Board of Chung-Ang University" with written informed consent from all subjects. All subjects gave written informed consent in accordance with the Declaration of Helsinki. The protocol was approved by the "Institutional Review Board of Chung-Ang University."

\section{AUTHOR CONTRIBUTIONS}

All authors designed the study, collected the data, interpreted the results, read and corrected the draft versions of the manuscript, and approved the final version. JK drafted the manuscript with supervision of KK and J-HL.

\section{FUNDING}

This research was supported by the Ministry of Education of the Republic of Korea and the National Research Foundation of Korea (NRF-2015R1D1A1A09061029). This manuscript is a condensed version of the first author JK master's thesis.

Berridge, K. C. (2009). 'Liking' and 'wanting' food rewards: brain substrates and roles in eating disorders. Physiol. Behav. 97, 537-550. doi: 10.1016/j.physbeh. 2009.02.044

Boyce, J. A., Kuijer, R. G., and Gleaves, D. H. (2013). Positive fantasies or negative contrasts: the effect of media body ideals on restrained eaters' mood, weight satisfaction, and food intake. Body Image 10, 535-543. doi: 10.1016/j.bodyim. 2013.07.002

Brignell, C., Griffiths, T., Bradley, B. P., and Mogg, K. (2009). Attentional and approach biases for pictorial food cues. Influence of external eating. Appetite 52, 299-306. doi: 10.1016/j.appet.2008.10.007 
Carver, C. S., and Scheier, M. F. (1982). Control theory: a useful conceptual framework for personality, social, clinical and health psychology. Psychol. Bull. 92, 111-135. doi: 10.1037//0033-2909.92.1.111

Cisler, J. M., and Koster, E. H. (2010). Mechanisms of attentional biases towards threat in anxiety disorders: an integrative review. Clin. Psychol. Rev. 30, 203216. doi: 10.1016/j.cpr.2009.11.003

Costa, P. T. Jr., and McCrae, R. R. (1992). Revised NEO Personality Inventory (NEO$P I-R)$ and NEO Five-Factor Inventory (NEO-FFI) Professional Manual. Odessa, FL: Psychological Assessment Resources.

Dobson, K. S., and Dozois, D. A. (2004). Attentional biases in eating disorders: a meta-analytic review of stroop performance. Clin. Psychol. Rev. 23, 1001-1022. doi: 10.1016/j.cpr.2003.09.004

Heaven, P. C., Mulligan, K., Merrilees, R., Woods, T., and Fairooz, Y. (2001). Neuroticism and conscientiousness as predictors of emotional, external, and restrained eating behaviors. Int. J. Eat. Disord. 30, 161-166. doi: 10.1002/eat. 1068

Heinberg, L. J., and Thompson, J. K. (1995). Body image and televised images of thinness and attractiveness: a controlled laboratory investigation. J. Soc. Clin. Psychol. 14, 325-338. doi: 10.1521/jscp.1995.14.4.325

Herman, C. P., and Polivy, J. (1975). Anxiety, restraint, and eating behavior. J. Abnorm. Psychol. 84, 666-672. doi: 10.1037//0021-843x.84.6.666

Herman, C. P., and Polivy, J. (1980). "Restrained eating," in Obesity, ed. A. Stunkard (Philadelphia, PA: W. B. Saunders), 208-225.

Hermans, D., Vansteenwegen, D., and Eelen, P. (1999). Eye movement registration as a continuous index of attention deployment: data from a group of spider anxious students. Cogn. Emot. 13, 419-434. doi: 10.1080/026999399379249

Hollitt, S., Kemps, E., Tiggemann, M., Smeets, E., and Mills, J. S. (2010). Components of attentional bias for food cues among restrained eaters. Appetite 54, 309-313. doi: 10.1016/j.appet.2009.12.005

Kim, J., and Lee, J. H. (2016). The effect of neuroticism level on restrained eaters' self-enhancement and eating behavior following exposure to thin-ideal images. Korean J. Clin. Psychol. 35, 195-214. doi: 10.15842/kjcp.2016.35.1.010

Krahé, B., and Krause, C. (2010). Presenting thin media models affects women's choice of diet or normal snacks. Psychol. Women Q. 34, 349-355. doi: 10.1111/ j.1471-6402.2010.01580.x

Miller, M. A., and Fillmore, M. T. (2010). The effect of image complexity on attentional bias towards alcohol-related images in adult drinkers. Addiction 105, 883-890. doi: 10.1111/j.1360-0443.2009.02860.x

Mills, J. S., Polivy, J., Herman, C. P., and Tiggemann, M. (2002). Effects of exposure to thin media images: evidence of self-enhancement among restrained eaters. Pers. Soc. Psychol. Bull. 28, 1687-1699. doi: 10.1177/0146167022 37650

Roberts, A., and Good, E. (2010). Media images and female body dissatisfaction: the moderating effects of the five-factor traits. Eat. Behav. 11, 211-216. doi: 10.1016/j.eatbeh.2010.04.002

Rofey, D. L., Corcoran, K. J., and Tran, G. Q. (2004). Bulimic symptoms and mood predict food relevant stroop interference in women with troubled eating patterns. Eat. Behav. 5, 35-45. doi: 10.1016/s1471-0153(03)0 0058-8

Rusting, C. (1998). Personality, mood, and cognitive processing of emotional information: three conceptual frameworks. Psychol. Bull. 124, 165-196. doi: 10.1037//0033-2909.124.2.165

Stice, E. (2001). A prospective test of the dual pathway model of bulimic pathology: mediating effects of dieting and negative affect. J. Abnorm. Psychol. 110, 124135. doi: 10.1037//0021-843x.110.1.124

Strahan, E. J., Spencer, S. J., and Zanna, M. P. (2007). Don't take another bite: how sociocultural norms for appearance affect women's eating behavior. Body Image 4, 331-342. doi: 10.1016/j.bodyim.2007.06.003

Strauss, J., Doyle, A. E., and Kreipe, R. E. (1994). The paradoxical effect of diet commercials on reinhibition of dietary restraint. J. Abnorm. Psychol. 103, 441-444. doi: 10.1037/0021-843x.103.3.441

Talesfore, C. M. (2008). The Thin Fantasy: An Examination of a Potential Factor in Mass Media's Self-Enhancing Effects on Restrained Eaters. Ph.D. thesis, University of Hawai'i, Honolulu.

Van der Zee, K. I., Buunnk, B., Sanderman, R., Botke, G., and Van der Bergh, F. (1999). The big five and identification-contrast processes in social comparison in adjustment to cancer treatment. Eur. J. Personal. 13, 307-326. doi: 10.1002/ (sici)1099-0984(199907/08)13:4<307::aid-per342>3.0.co;2-r

Warren, C. S., Strauss, J., Taska, J. L., and Sullivan, S. J. (2005). Inspiring or dispiriting? The effect of diet commercials on snack food consumption in high school and college-aged women. Int. J. Eat. Disord. 37, 266-270. doi: 10.1002/ eat. 20100

Wegner, D. M. (1994). Ironic processes of mental control. Psychol. Rev. 101, 34-52. doi: 10.1037//0033-295x.101.1.34

Werthmann, J., Roefs, A., Nederkoorn, C., Mogg, K., Bradley, B. P., and Jansen, A. (2011). Can(not) take my eyes off it: attention bias for food in overweight participants. Health Psychol. 30, 561-569. doi: 10.1037/a00 24291

Widiger, T. A., Costa, P. T. Jr., and McCrae, R. R. (2002). "A proposal for Axis II: diagnosing personality disorders using the five-factor model," in Personality Disorders and the Five-Factor Model of Personality, 2nd Edn, eds P. T. Costa Jr. and T. A. Widiger (Washington, DC: American Psychological Association), 431-456. doi: 10.1037/10423-025

Conflict of Interest Statement: The authors declare that the research was conducted in the absence of any commercial or financial relationships that could be construed as a potential conflict of interest.

Copyright (c) $2019 \mathrm{Kim}$, Kim and Lee. This is an open-access article distributed under the terms of the Creative Commons Attribution License (CC BY). The use, distribution or reproduction in other forums is permitted, provided the original author(s) and the copyright owner(s) are credited and that the original publication in this journal is cited, in accordance with accepted academic practice. No use, distribution or reproduction is permitted which does not comply with these terms. 